\title{
"Hard Copy" Building Model versus Digital Webpage Serving the Representation of Concepts in Architecture Design and in Scenographic Design
}

\author{
Maria Bostenaru Dan ${ }^{1}$ \\ ${ }^{1}$ Centre for Risk Studies, Space Modeling and Dynamics of Terrestrial and Coastal Systems, University of \\ Bucharest, Bucharest, Romania \\ Correspondence: Maria Bostenaru Dan, Faculty of Geography, Centre for Risk Studies, Space Modeling and \\ Dynamics of terrestrial and coastal systems, University of Bucharest, Bucharest, Romania. Tel: 40-732-54-700. \\ E-mail: Maria.Bostenaru-Dan@alumni.uni-karlsruhe.de
}

Received: December 19, 2014

doi:10.5539/res.v7n3p210

\author{
Accepted: January 23, 2015 Online Published: February 25, 2015 \\ URL: http://dx.doi.org/10.5539/res.v7n3p210
}

\begin{abstract}
We will talk about how the same concept can be represented differently in the environment of building a model of the designed object/installation versus the digital representation in a webpage in case of a building and of scenographic installations. The digital representation is more than just the digitalization, as it involves a conversion of the concept. The building we try to represent, "AQUA MEGA" is an aquarium and museum of water. For the project, apart of drawn pieces, we built an urbanism project which included the volumes and the landscape design, as well as a building model where the construction was detailed: the aquaria but mainly the building of the museum, out of laminated wood joints in free form which at the same time it is the ceiling of the hall between the aquaria. This hard copy model in different diminished scales represent how the concept of the museum of water, which aims at the ambivalence of the element, between heritage and hazard, between building vulnerability and being a vulnerable habitat, translates into a building. The atmosphere could not be built, and the way spatiality can be read is limited, the accent being on volumes. At the same time we built a webpage for the museum of water, designing a round trip along similar aquarium constructions in the world we visited, and explaining the concept through text. It makes use of multimedia techniques in making it interactive. The first scenographic installation is that of the "Rediscovered space". The model is this time 1:1, and it represents the door to this space. It works with sand, which covers the door like forgetting, and with coloured light, which passes behind the door, to awake the memory. In sand also boxes with elements addressing the senses are buried and to be diggen out like by archaeologists. It is the concept of these boxes addressing the senses to which the multimedia webpage goes back. Because also for this project we developed a web page, in frame of an exhibition. In this the model is documented, as it is the bringing to paper of the concepts, playing with illustrated and with black surfaces the contours of which inspire the feeling of the spaces. It is this where the 3D digital model in the webpage comes back: the models of the spaces are boxes, like those in the sand, using walls instead of contours to suggest feelings. The second scenographic installation addresses augmented reality. We designed an array of "doors" like before, where the visitors can immerse into the photographs projected, mirrored or shadowed. The digital version goes for stereo images, involving the 3D model and the photograph. Finally we approached the green wall. While pockets on skeletons to build a green wall can be the boxes of before, for a digital version we can dug among the thorns from Grimm/Perrault s sleeping beauty, to find shapes of spaces, like in a Paradise Garden concept, for which we have a model, for example with an image map.
\end{abstract}

Keywords: architecture, scenography, landscape, web page, map, navigation

\section{Introduction}

In 2013 we visited the exhibition "Digital art conservation", which resulted from a European project. "Digital Media Art in the Upper Rhine Valley. Conservation-Restoration-Sustainability" is a European project that run from January 2010 to December 2012 by ZKM (Centre for Art and Media) and five partners from France and Switzerland in the upper Rhine valley. The exhibition, entitled: "Digital Art Conservation. The Challenges of Conservation" curated by Bernhard Serexhe, Chiara Marchini Camia, and Arnauld Obermann was presented at various partners. It features the ten case studies from the project, from iconic media art pieces such as Jeffrey 
Shaw's Legible city to contemporary Macromedia Director works such as Antoine Schmitt's "still living". Older works display the problem of hardware which became difficult to preserve, sometimes of analogue signals, which draws attention to the future of contemporary. Some works were updated in the frame of the project. A book was published afterwards, with the same title, on the theoretical background. A book has been published following the project (Serexhe, 2013). Digital art preservation has been also previously approached (Garcia et al., 2010) and is a problem of conservation in the arts as important as the conservation of mural paintings.

We worked ourselves with early versions of Macromedia Director, and, in the current project we work on, we try to adapt the maps concept from such an early movie, as well as the time slider. However, in this paper we will talk about how the same concept can be represented differently in the environment of building a model of the designed object/installation versus the digital representation in a webpage in case of a building and of scenographic installations.

When working with the early multimedia versions back in 2000, we had the occasion to review the early developments of computers to multimedia instruments, according to Hughes (1999). Many of the links accessing the examples do not work anymore. These can be summarized as follows:

- From time sharing to PC key events are "playwords" (the precursors of computer games from the 70s such as Zork), domesiticising the world of the text (transformation in hypertext sometimes through dedicated tools such as "StorySpace"-editors such as StorySpace are the precursors of today's ontologies, but the hypertext organization of texts has been experimented in the 1970s also in architecture books such as Alexander et al., 1977), the beginnings of virtual reality, visualization of abstract ideas (the begin of graphics), "musical space" (120 years of electronic music" of Simon Crab), but also desigining and investigating the brain (ex. by means of chatbots). We want to highlight the development of hypertext since we employed its further development in this paper of us, creating webpages where the hyperlink is done for example by image maps, but also in classical ways. Image maps were made possible by the development of graphics;

- The begins of a mass media - interactive video (simulations - for example to present World Heritage, as in early CDs of Armchairtravel which presents London highlights-Parliament, St Paul's Cathedral http://www.armchair-travel.com/-we own such a CD, but also VR games, "Visual Almanac" of Apple—a presentation of Physics, BBC "Domesday Disk" to the $900^{\text {th }}$ anniversary of William the Conqueror Domesday Survey in England - see Stewart Brand THE MEDIA LAB);

- Opening to the mass - from the Mac to CD ROM (Guide, WorldBuilder-a transposition by Bill Appleton of Adventure/Zork into graphics; for examples of WorldBuilder Ray's Maze page/still available today (http://www.semitech.com/marc/ray.html) could be consulted, VideoWorks, Hypercard, Amiga and the author system Mandala - which allowed immersion in a virtual word, and finally VideoWorks/Director and the M-word). Here it is to highlight that Hypercard, a work of Bill Atkinson, was the first to gather a developer community. Unlike the name, it was not thought for hypertext, but for programming. We had the occasion to play Amiga games such as Dyna Blaser - unlike today's PCs they allowed multiplayer at the same computer via joy stick. Video Works was developed 1987 by a small software company in Chicago (MacroMind, led by Marc Canter, who left 1990 MacroMedia). It was still to be recognized in the $7^{\text {th }}$ version of MacroMedia Director (sprites). Later on, Macromedia Director went over to Adobe. We want to highlight this development since we employed in our digital representations Director. While some of the other environments became niche products, to the time of the review the produce developed from VideoWorks took over the market. Macromedia developed then Macromedia Flash. Flash took over the web to the detriment of Director, which, also it had a web version, was primarily performant for CD ROMs. We did a comparison between HyperCard and Director, based also on the fact that both have an animation table and a developer script language. At the turn of the millennium the $\mathrm{M}$-word was a big word. It seemed that the jobs of the future will be on the internet, and that publicity will bring the income. The arrival of the CD ROM as storage space enhanced this. It also seemed that digital means will replace print means. 15 years after hard copy is still alive, and we try in our work to show how a multimedia work can be also done combining the media art with hard copy elements (the photographic exhibition).

\section{Methodology}

The digital representation is more than just the digitalization, as it involves a conversion of the concept. For this we only approach for digital art the concept of 3D, as it results from the $2 \mathrm{D}$ morphogenesis. To convert the plastical expression used in one medium into one used in another medium, one can refer to the way Filoteanu and Marian (2000) suggest to use point, line, surface and volume as elements of artistic language.

In the first case study, the building converted to webpage, the building operates with volumes and with spaces delineated by these volumes. The materiality of the volumes is also a mean of expression. The space is 
physically explored. Turning to the webpage, the $2 \mathrm{D}$ composition and the interaction are the means of communication. The space of the webpage is also explored, by means of online navigation (rolling over and click). The distances are instantaneously set behind. The conversion of the concept included translating the functional organization in the building (Figure 1-drawing, Figure 2 scale model) into the functional organization of the webpage (Figure 3-5), which has to reflect in the plastical experience of moving from one space to another or from one page to another. In the webpage we used different programming approaches, which included HTML editing, including image maps to visualize the navigation in physical space, the inclusion of multimedia elements such as photos and video, and for creating more windows to facilitate the simultaneous access to more navigation items the HTML editing with frames as well as JavaScript for multiple windows. All was done with a text editor.

In the second case study 2D space was converted to 3D space (Figure 6). 2D space first existed physically, as collage. In the collage it was worked with the plastic language element of the surface. The line determined by the boundary of the surface suggests an artistic expression as Filoteanu and Marian (2000) explains. Translated to 3D space only the line was kept for morphogenesis. The line becomes 3D line, with a height, and is defining spaces, as in the first case study in the real building. This space will induce the feeling to be suggested. Additionally there are photos of a model in the physical space, and videos exemplifying the concept of this model. The videos and the 3D models on computer were done using the software Cinema 4D. The programming of the navigation in the real time 3D application embedded in the webpage was done with Macromedia Director 8.5. This allows the webexport and can be visualized with a plugin called Shockwave. For the programming of the 3D items a script called Lingo was employed. This one follows openGL rules. Also here we employed apart of including the multimedia elements of film and photo, navigation options with frames and pop-up windows through JavaScript.

In the second scenography installation the multimedia elements and the physical model merge (Figure 8-9). The computer programmed multimedia will be projected on screens and becomes part of the physical model. As software for obtaining the projected content DTP software is used to convert the pictures, and then presentation software to project. This presentation software can also be Macromedia/Adobe Director. In our development of a presentation software we also considered navigation in advancing regressing between slides, but also the option of moving items in a slide, similarly to the software ACDSee. Another option would be to use Prezi, which allows a zoom of the image, using a similar technique to Macromedia Director, on the basis of Flash, the next product of the company. This is suitable to show images and details of images.

In the third case study we turn towards converting the concept of a garden. It is not a usual garden, but a garden of the imagination, the garden of Paradise. As such, it is a reverse of the virtual scenographic installation in the second case study. Instead of making boxes which suggest feelings through considering the 3D line, the 3D line becomes here boundary. We work again with surface expression according to Filoteanu and Marian (2000), but the surface becomes volume. The expressive spaces are cut into the hedge. The expressive line is that of the boundary. This way spaces like in the first case study are obtained. In the digital representation the surface becomes planar one, and image maps are used for navigation again (Figure 10). The project as such is embedded into a webpage displaying more projects from the portofolio, and builds such a whole. The software used is the text editor for HTML, including images and frames for navigation. As in the first case the background image is used, which makes use of the repetition of a stylized image, also a concept of artistic plastical language.

In the first and the third case study the physical model was built in reduced scale (Figure 2, 11), but it could be a building as well. In the second case study the physical model was built 1:1. For our ongoing project there are lessons to learn, since we work with digital representation of maps, but the urban space is also a physical space $1: 1$. Strategies can be represented by highlighting a certain area of a map at a different scale, but when we want to highlight in physical space, a vision for filling public space with life is needed. On this scenario and strategy development worked Helmut Kahn (1966). Similarly, navigation in physical space can be connected to navigation in virtual space by connecting GPSed images, as Amoroso et al. (2013) have shown using IPhone photography.

\section{Case Studies}

\subsection{Architecture Design}

The building we try to represent, "AQUA MEGA", is an aquarium and museum of water, a diploma work refereed by Rüdiger Kramm (architect) and Henri Bava (landscape architect). For the project, apart of drawn pieces, we built an urbanism project which included the volumes and the landscape design, as well as a building model where the construction was detailed: the aquaria but mainly the building of the museum, out of laminated 
wood joints in free form which at the same time it is the ceiling of the hall between the aquaria. This hard copy model in different diminished scales represent how the concept of the museum of water, which aims at the ambivalence of the element, between heritage and hazard, between building vulnerability and being a vulnerable habitat, translates into a building. The atmosphere could not be built, and the way spatiality can be read is limited, the accent being on volumes. At the same time we built a webpage for the museum of water, designing a round trip along similar aquarium constructions in the world we visited, and explaining the concept through text. It makes use of multimedia techniques in making it interactive.

In 1912 it was inaugurated by Emperor Wilhelm II the lower port, as the second port of Frankfurt. With this and with the railway station district a development began development by integrating urban Frankfurt to that huge knot which is today: a metropolis of commerce, banks and services.

Frankfurt is the spatial and economic center of the Rhine-Main region. In $2 \%$ of the area $14 \%$ of the population live and $27 \%$ of the employees work. The economic strength of the city is the engine of development for the regional economic structure, characterized by the services sector.

The region has benefited for decades from the high site quality and economic dynamics of Frankfurt, while the city increasingly took the social and financial burden for the entire region. Urban development planning for Frankfurt as a city of a compression chamber is therefore always put up in relation to the development of the entire region. The virtually uncontrolled suburbanization in the region is a threat to sustainable development. The importance of the location increases the environmental factor. Above all, the center of the conurbation vitally needing the large scale networked green and landscape areas to be developed.

\subsubsection{The Museum Embakement}

The Frankfurt Museum Embankment was a prime example of a city policy that after the time of the new citizen-oriented initiatives. First and foremost, it was about a sequence of citizens villas. The "face" of the city on Main was done towards a certain attempt to rescue from impending demolition. Frankfurt through the design of the right bank in the 19th Century completely turned its face to the Main. Between 1980 and 1990 in Frankfurt am Main, 13 new museums have been created. They are designed almost exclusively by highly talented and prominent architects and show something like a cross-section on the history of European and North American architecture of the past decade. The project caused a stir around the world found a wide response and bore the reputation of the city of Mecca in contemporary architecture.

The buildings are, whenever possible, connected by parks together. Apart from the ramparts and the pedestrian concept the Museum embakement is defining the third moment of the inner city and characterizing structure. It was developed by connecting the north and south shore area to an urban backbone in a delightful contrast to the business and shopping area. The formation of a new city center and the rest of the culture with the Main as the central axis is one of the most important urban development projects of the postwar period.

\subsubsection{The Green Belt}

The project GreenBelt Frankfurt aimed to protect remaining, contiguous green spaces around the city from the access of settlement activities rooted in the time of the first Modern in Frankfurt am Main, in the approaches of urban settlement office at Ernst May settlement planning was accompanied by open space. The green belt was thought of in the 1970s due to the suggestions of Till Behrens and it was Tom Koenigs in the early 1990s who moved it at a rapid swing in the public eye. Only a closed ring of open space has been developed as an abstract symbol of landscape.

From March 1990 to March 1991, in the Green Belt project year, the Green Belt Project Office has processed an approach to dovetail space and urban development on the edge of town. The Academy provides landscape architects and teams of students and professors from home and abroad who have developed designs for four types of areas (N, S, E, W). The physical landscape of the city was: on the breaks of the spaces and uses, on the missing links and connections as well as superposition of settlement and clearance, so the conflicts between buildings and landscape are solved for recreation. In the design area East, almost all participants in the port restricted to a few interventions that have the potential of the free water surface set in a new reference to the Green Belt, as well as single items that can be linked either through visual references or over roads and bridges. The Frankfurt city council meeting decided in November 1991 the GreenBelt Charter through which almost a third of the area of Frankfurt was protected. The Green Belt Constitution was set in force since November 1991. The GreenBelt Frankfurt GmbH started in November 1992 their work. With its inception in 1993, the phase of concrete development projects began involving competent departments. The total green belt area was broken down into manageable project areas and processed successively. 
The green belt is also part of the city, the Rhine-Main region and the transition between the two. The forest in the south, the floodplains of Nidda and Main and the hills to the north-east are the defining elements of the green belt. They divide and distinguish the spatial image of the city. The green belt is connected by radial and circular connections to the neighborhoods of the inner city. The green belt, the inner city green links and the outer green areas are the parts of a coherent and complementary urban green system. This provides the opportunity to link through the green belt, the urban green spaces with the backed regional green spaces and to achieve a sustainable improvement of the environment for the entire Rhine-Main region.

The green belt will in future serve to open borders and districts of the country to join her network - among themselves, with the city center and the region. The urban politics turns to the design and development of transition zones between the core city and the periphery.

The plans worked out in the Green Belt visible cracks, edges and transitions in their particular visual, social and environmental importance. The green belt is neither nature nor landscape, but urban expansion in progressive sense. The image of nature is a structure of the "pristine" and "cultivated", the novel uses the woven edge of town. Building on the edge of the charm of the building is located on the water. The Green Belt Frankfurt another edge was highlighted: the boundary between city and country.

Examples of successful green belt project work are: the "Rebstock Park" (Architect Eisenmann, consulting architect Speer \& Partner) in the west of the city center (district at the inner edge of the green belt) in the South social housing at the inner edge of the forest, in the east, at a Main embakement park bound, the district Kaiserlei (DW Architect Dreysse).

The Rebstock Park is an inner-city green connection between Nidda, Alleenring and ramparts. The "folded" linking town and countryside to make the idea of a productive, non-ornamental landscape and overlay these with urban (work, home, leisure, \& education). So it was to principles that were applied in the green belt project. The district Kaiserlei (competition in 1992) is formed. Between Frankfurt and Offenbach's green belt green ring, the urban forest and the Main Landscape link on municipal boundaries. The Imperial territory touches the green belt at its interface with the river landscape of the river Main. For the opposite port areas a similarly related urban landscape was expected.

The time of the innovative strategies continues until the present. Frankfurt is involved with a variety of initiatives in the field of architecture and urban planning.

In the past years, in Frankfurt the context for living and working, for the transport and open space development, the "Living in the City" as a whole, to be redefined.

Among the most interesting, and most attractive location factors the most promissing in Frankfurt include the river and due to its strategic location and areal extent weight (exposure, location on the River City near us), especially the port facilities of the west side and the eastern port.

The Frankfurt ports can now be central to a changing structural policy. The conversion of previously industrial or military sites in the city is seen as the opportunity to expand existing green and open spaces and to network with each other. So this will follow on historical models of integrated landscape and settlement planning. The Main river be developed into a continuous urban recreation park ("Main embakement park"), so that the city may open up more to their river back.

Living on the water is in Frankfurt one recyclable at the city's founding tradition. They followed up on the project for urban development on the east side.

Frankfurt on the Main and not on two quays. A generous city interior green area can be achieved by the orientation of the city to the river with continuous riparian zones.

On the northern bank of the Main are still missing key projects a future-oriented urban redevelopment.

Within the city of Frankfurt is a marked difference in the spatial development from east to west. The-art facilities and areas of the West (trade, banking district, Railway Station, West End) are in the east, despite the same proximity to the city center ( $3 \mathrm{~km}$ radius) there is no equal.

Communal Marketing is a new district it for urban development Frankfurt Ost GmbH to restructure the Frankfurt east side. In 1992, the city representative council decided for the east side, the pursuit of a study of AS \& P (Albert Speer \& Partner GmbH) in order realization and further development. They determined the urban frameworks for the development of the "living quarters under the harbor". The Frankfurt harbor is very active, so far had the interests of affected companies are given special consideration. Of the alternatives was agreed to develop east-west direction, which provides for a housing development under port and a compact commercial 
higher port was preferred.

\subsubsection{Approach}

Development conditions: Living on the river, Use as recreation area, Integration River Green Belt and urban space, straightening the urban image of the 1900s.

Frankfurt Green Belt area reaches its interface with the Main river landscape. This space Main and Green Belt promenade and large areas to be treated as an open green space and urban centers. The two systems, the Green Belt and port touch points, but must not influence each other.

Important for the concept of green and free surfaces are the existing potential in the existing trees on Südmole project, along Franziusstraße. They were built so that the opportunity was provided access to live water element.

Space gets more value by targeting the river. A port promenade is created by cleaning and moving Main bank by protecting street opposite and by emphasizing the harbor promenade head by taking the existing grounds. The structure is preserved, but enhanced.

Alignments of trees continues with a second level, as a metamorphosis in the square outside the museum. Pavements and integrates various organic continuous folded structure functions. For parking using the rules of 22.04.1993 of Frankfurt. Due to the proximity of the port basin a second basement was dropped, the basement is for technical uses for aquarium tanks. There is again a structure, which has a denser core and dissolves at the edges. It is the same structure that describes the building, which defines the place field complex.

Head port means to an end, there must be driven over the bridge. Different places of the stairs mark this transition. The beachhead compliance is possible for water to be lived in different ways. There is a particular relationship with the building.

The basic elements of landscape (the lining of poplars, water) are areas within which the functions overlap. Where there is potentially valuable nature it is not built. Building is seen as compensation-former industrial gray surfaces are hidden from the building and thereby create a beautiful landscape view.

Genius loci in port means mostly devoid of trees piers, a clear and sharp cut and for free, direct to the river.

The neck was seen in almost all proposals for report that green tongue. The building is intermediate position between two factors: green in crowded and science institutions aimed at integrating research and education.

The museum basin water was placed between the port and road access and thus mediates between different requirements. In this place manifests itself clearly to passers-port theme Honsell bridge. Honsell bridge and building do not compete, but emphasize each other.

A particular point of urban texture gets importance. A small market that is oriented to the city and creates relationships of view. This is protected, just like the design for Green Belt, contrary to trends to change design of housing and services. Gap sites cannot, experience is limited to carpet.

Buildings, road and pedestrian and bicycle paths should meet existing cranes in a language port and industrial area. River to integrate building and other villas on the southern bank, the port has a different face. Thus they react in scale to port facilities. On the port side there was no piazza designed for the museum. This building increases as a stronghold of water, sharp cuts are sharp and the mirror is used instead of shadow areas. On the side facing Main it develops as a fold in the opposite direction of the Honsell ramp, which becomes visible inside the soil layer.

\subsubsection{Urban Concept}

In recent years it could be redefined in Frankfurt the framework for housing and employment development in movement and space for "city living space". Among the most attractive place in Frankfurt are river factors and especially the port.

In the fall there is Frankfurt spatial development from east to west. Fair, station, Westend do not have anything of equal value corresponds to the east. Therefore the urban development in the eastern port has some importance.

Frankfurt treated area is exposed in the east port. The Green Belt Frankfurt at the river is crossing the landscape of tomorrow. According to this is it is seen in the connection of two systems: on the one hand the shore landscape as urban space, especially the bank buildings as museums, on the other hand the Green Belt with interlocking space and urban development on the urban edge. Basis for further processing zone was an analysis of design and approaches that affect: principles that were applied for bank museum and the Green Belt, development strategies for Eastern port (feasibility study of Albert Speer), the relationship with the opposite district the new Kaiserlei as exemplary design by integrating the Green Belt proposals and final study by David 
Chipperfield. The urban concept developed from new situation created by Chipperfield's design and location of existing differentiated look. Out of Chipperfield's proposal we took in consideration important elements such as:

- Building self-reporting and free spaces;

- Orientation pools, linearity, strong edges;

- Strong north-south passage through different axes (on the west side emphasized the edge axis is accentuated only by industrial facilities maintained - cranes - Honsell bridge. Buildings designed to accentuate this axis and simultaneously enters into a dialogue with structural fields where show massive appearance of these buildings);

- Siedlung concept of parallel strips that are filled with various functions;

- Shore band, continually developed as a park, which is tangent to different sides. There is a prominent side park between the city and the river, but a sequence of events listed gardens.

The landscape tourism concept continues to a lesser extent the principle of cutting through bands with different pavements. This is a denser urban area to dissolve the edges, where the building passes in the street space.

Construction is seen as compensation. Currently it is being built where there are is low natural potential. The port promenade is created by taking and strengthening existing elements, as well as compliance to the port head to accept differences between street and land. Museum basin water was placed between the port and the connecting street and thus mediates between different type requirements. In this place manifests itself clearly to passers: the theme port on the bridge Honsell. Building a major form object is a poignant volume, which has the effect of entry into the neighborhood. It grows in water and is cut to ground-a theme that is continued in the interior compliance. Some points in the urban tissue receive importance and thereby protect adjacent areas void of Chipperfield's design trends change design for housing and services. This was also higher principle of Green Belt: Urban construction means setting limits.

\subsubsection{Building Concept}

The absolute symbol for the element water is the tide. A great wave materializes the water museum, which is designed as the core of the building. Such a daring form can react better to megaforms of the landscape. Inside the museum there is a space where the walls, roof and floor are flowing into one another. This item can be experienced in its forms of water appearance (as water cycle: fog, glacier, rain, clouds, fountain). It is a concept that has been tried in the Netherlands (NOX, OOSTERUIS Associates: Water Worlds). The visitor may act alone and change the light sensors, color, projection and tone. One begins to run with the waves, but can stand up (in the laboratory) or to sink (the aquarium) ever. Characterize water weightlessness living space.

The museum floats in a large air space, whose boundaries are melting so out (with transparency) and to other spaces (with staggered levels and connection of bridge type). Two powerful rulers set them limits on the central element, which is characterized by a flow of vertical and horizontal. They serve as a container and manifest these limits contact with the outside world: This category comprises the laboratory program and numerous annexes (eg completion program multipurpose room where water may become more visible symbols). Like an iceberg only a small part of the inner life is expressed externally.

"Between" is the concept that best characterizes the area where the aquarium is experienced. This is the area of median house type. There is a positive space and a negative space. With a limited resemblance of the urban principles (here it is an enclosed interior space) tanks manifests themselves as positive objects, which define negative space. Negative space is primarily the atrium, inner life, which serves as a central place.

In the functional concept the aquarium and the museum intersect and intertwine. Living organisms and ecosystems in the aquarium are not only seen by laboratory research, but are also objects of museum exhibition. Body building is the museum as positive space opening to the aquarium space in both spatial and functional concept. It forms a negative space where the museum is not built but seen as a body that ceiling sculptural installation consisting of wooden beams visible rolling inward. It strongly contributes to the feeling of space ceiling and wall joints between water and arched body height accentuates the strait development. There are two different sides of the intermediate space part: water wall color, depth and ceiling living in amorphous form by taking modenature, which lives in texture. It seems that the visitor is immersed below the ceiling and experiences the so rich underwater life.

The other side of the aquarium is a totally different world. Nature is seen here through filters. Visitors perceive the outside world as a submarine (on the north) or parallel layering sinking of land (soil). Basins on the side street side are adequate deeper, the wider and this leads to a continuous vertical section view of nature.

The space between them is a principle of aquariums, where light comes through the walls (which is in aquariums) 
that constitute the point of interest. Working platforms suspended promenades and intermediate space and offers many opportunities for learning, just because it is staged throughout the aquarium. As "Habitat Path", which allows contemplation and understanding of the operating life of the spaces marked (and mostly endangered), in a succession of ecosystems thoroughly thought opposite relationship with related areas (such as testing laboratories, areas of pedagogy for children), where open but allow relationships with the central area. These individual basins, although always the same, are seen from various places, whole or in layers, near or remote.

Part of the scenography is the possibility to make get of the way and providing rest areas. Through it escapes from the aspect of aquarium design Disney area where compliance is based on the ability to judge blurring.

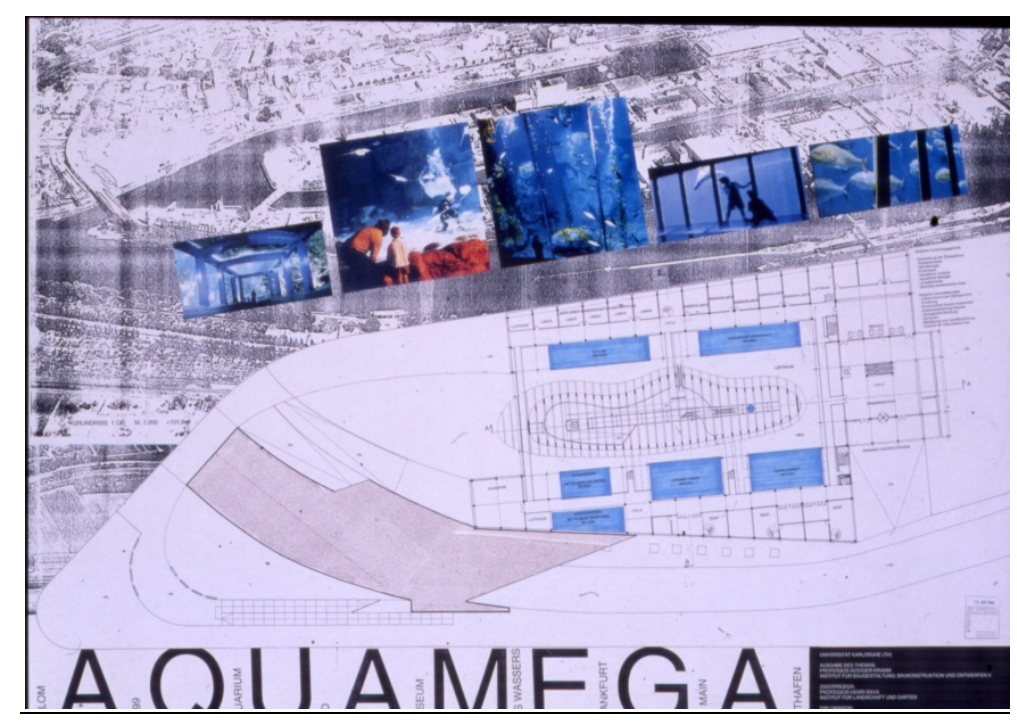

Figure 1. Proposed aquarium project-The plan in relationship to the harbour

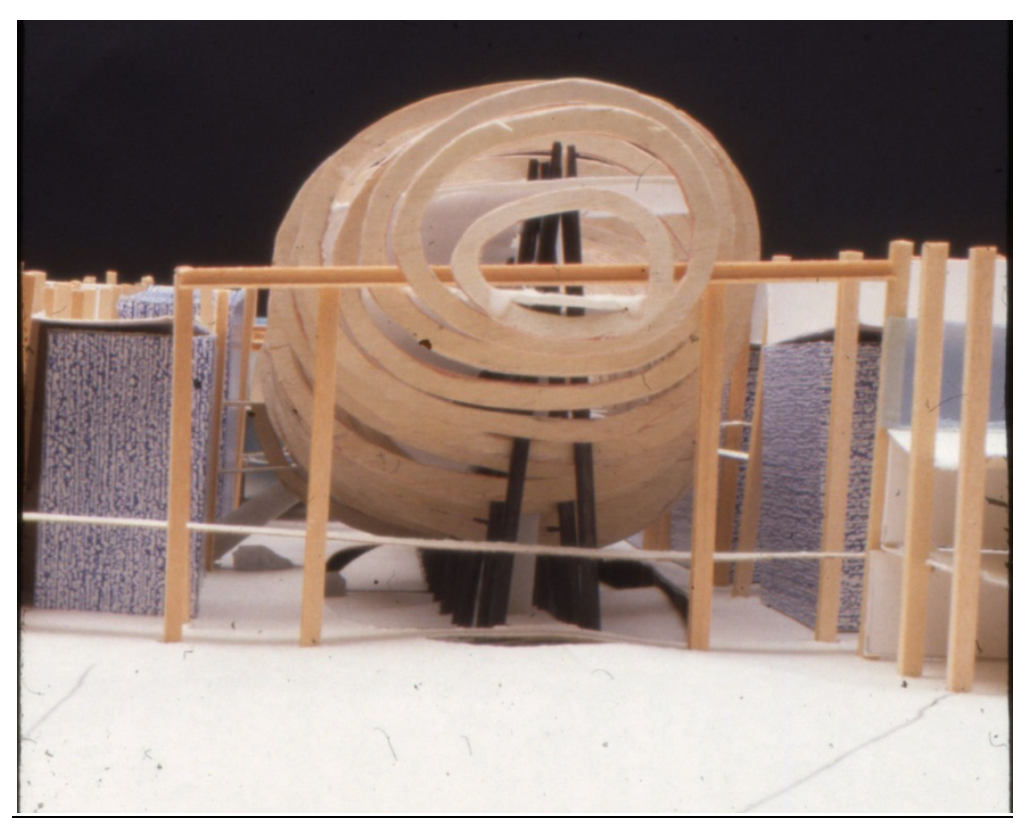

Figure 2. Hard copy model of the aquarium 


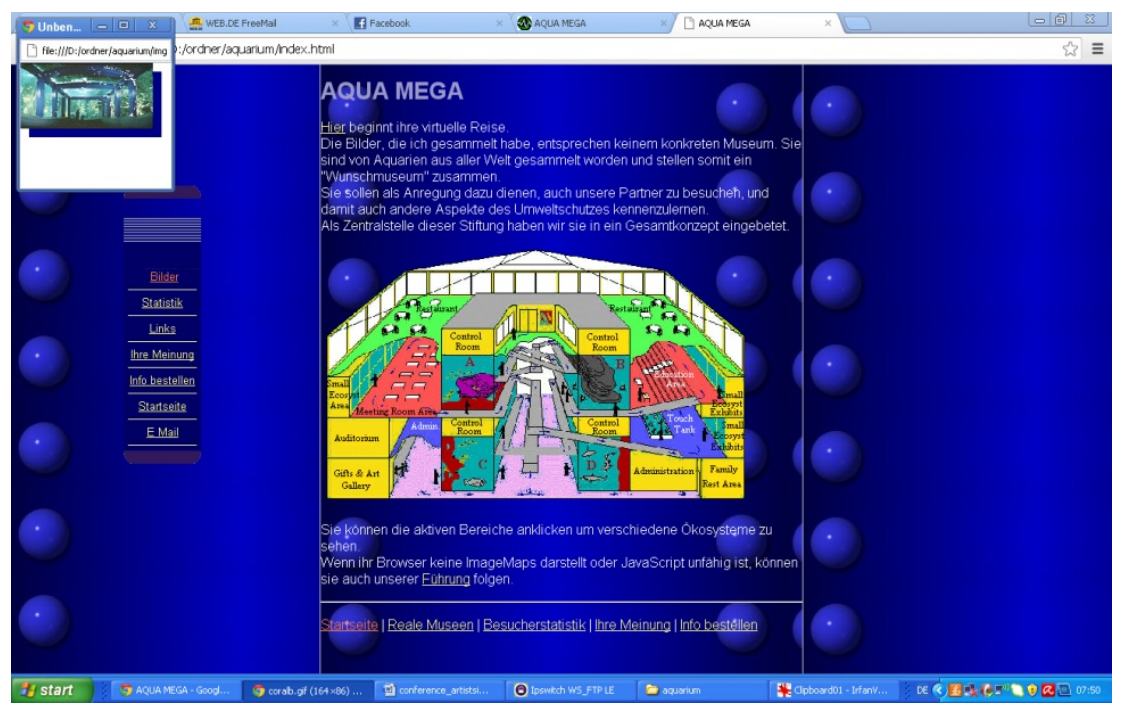

Figure 3. Web page of the project—proposed navigation based on spatial division

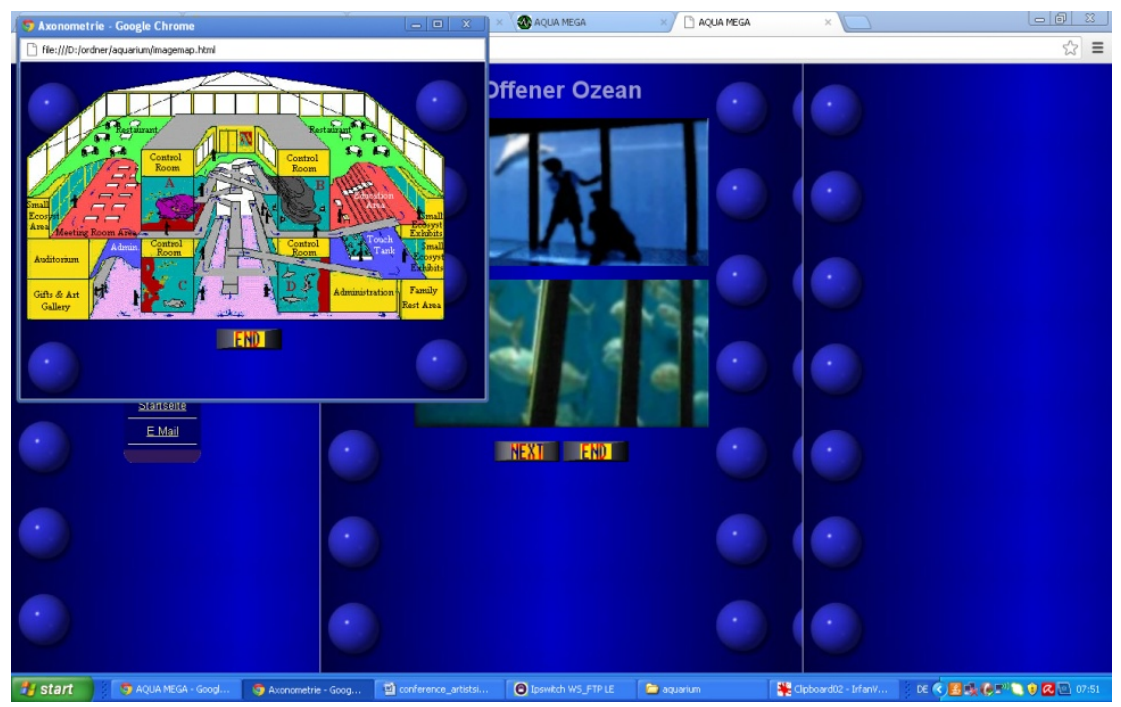

Figure 4. Further web page design of navigation in the aquarium

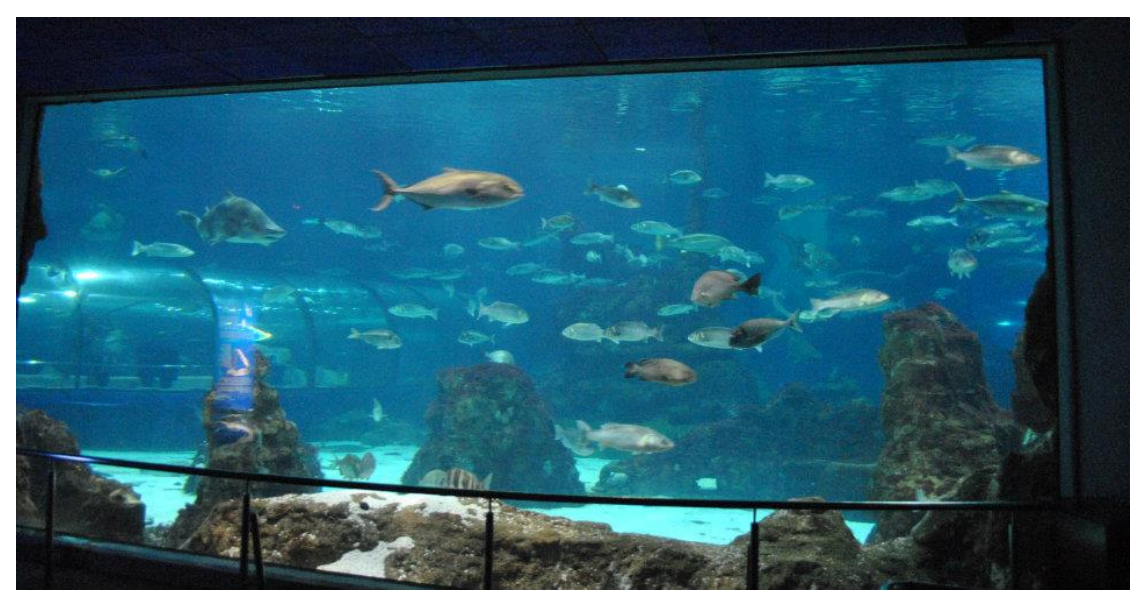

Figure 5. Example of an aquarium-Like the ones proposed in the project. Photo: M. Bostenaru 


\subsection{Scenography}

\subsubsection{Rediscovered Space}

The first scenographic installation is that of the "Rediscovered space". The model is this time 1:1, and it represents the door to this space. It works with sand, which covers the door like forgetting, and with coloured light, which passes behind the door, to awake the memory. In sand also boxes with elements addressing the senses are buried and to be diggen out like by archaeologists. It is the concept of these boxes addressing the senses to which the multimedia webpage goes back. Because also for this project we developed a page in frame of an exhibition. In this the model is documented, as it is the bringing to paper of the concepts, playing with illustrated and with black surfaces the contours of which inspire the feeling of the spaces. It is this where the 3D digital model in the webpage comes back: the models of the spaces are boxes, like those in the sand, using walls instead of contours to suggest feelings.

The research topic under the supervision of Daniel Libeskind was "Spaces of Encounter". The topic was not addressed first time here (see Libeskind, 2001 for the workshop in the USA), and it was part of a series of workshops of Libeskind for research at this location (see Voigt et al., 2010, including also a presentation of our work). We addressed in this theme issue the "rediscovered space". We made a 1:1 scale model of the entrance into this space. The door is partially covered by sand, and lit from behind: one can see that there is something behind it, but it cannot be opened. There are objects that addresses the senses, buried in the sand, and maybe they are the true door, which is made into something existing but forgotten. We present an installation symbolizing a unique encounter scenography. The door to the rediscovered space merged a long time ago with the environment. We have a door which is an old, which belongs to the past, until a space yet known was rediscovered, and have a light, the light of today, trying to rediscover, trying to show us a path, or even and what is behind the door, but what we have a glimpse of. When archaeologists are trying to find some signs of a culture that no longer exists, or at least not as it was, they collect some items, and include them in the museum and then say: "You cannot get a sense of culture ". The idea that is that very rarely that a museum of cultural attractions really reveals a culture we have built memories of. Sand boxes, and built before the door. To be dug in order to be found. The installation has links with other approaches in work: for example sanding in Namibia (Figure 7), a possible video and multimedia facility will be shown later. A multimedia installation was performed using boxes on the computer that can be such a development in a box a model in architectural language of the structure-space dialogue.

The concepts are illustrated in detail the subject of other works (Bostenaru, 2010). It is also the idea that the gates are gates lost memory space, which is accessed through the senses, as in Marcel Proust "In Search of Lost Time", and these senses are called objects that found in boxes buried in the sand, to be unearthed and opened. The door itself can not be opened, we see only light behind it which suggests that there is a space in which we have access. The multimedia version can be seen at http://bostenaru.natkat.org/hfgrundgang/ 


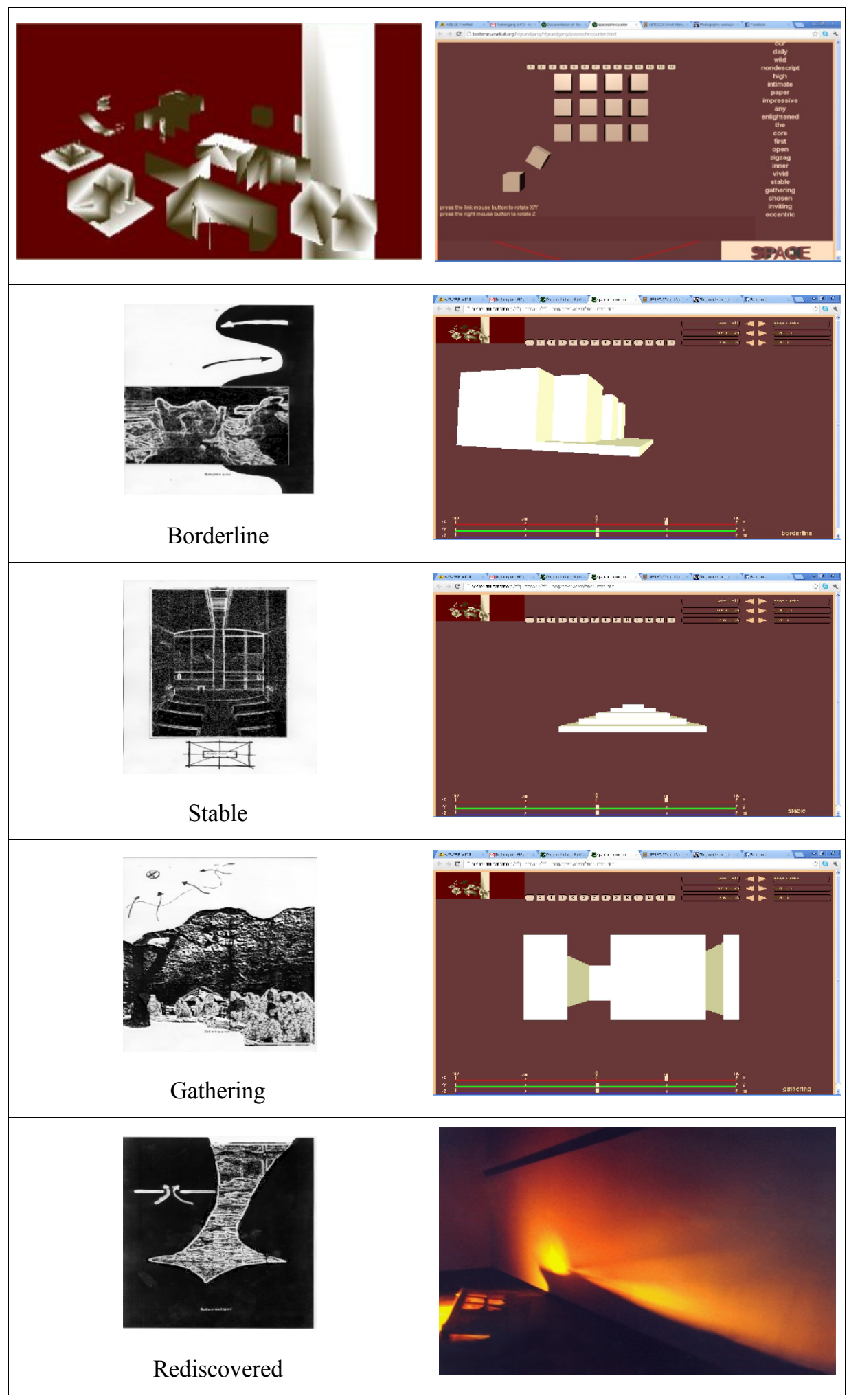

Figure 6. Transposition of spaces of encounter to the internet: modelling in Macromedia Director through morphogenesis from 2D idems 

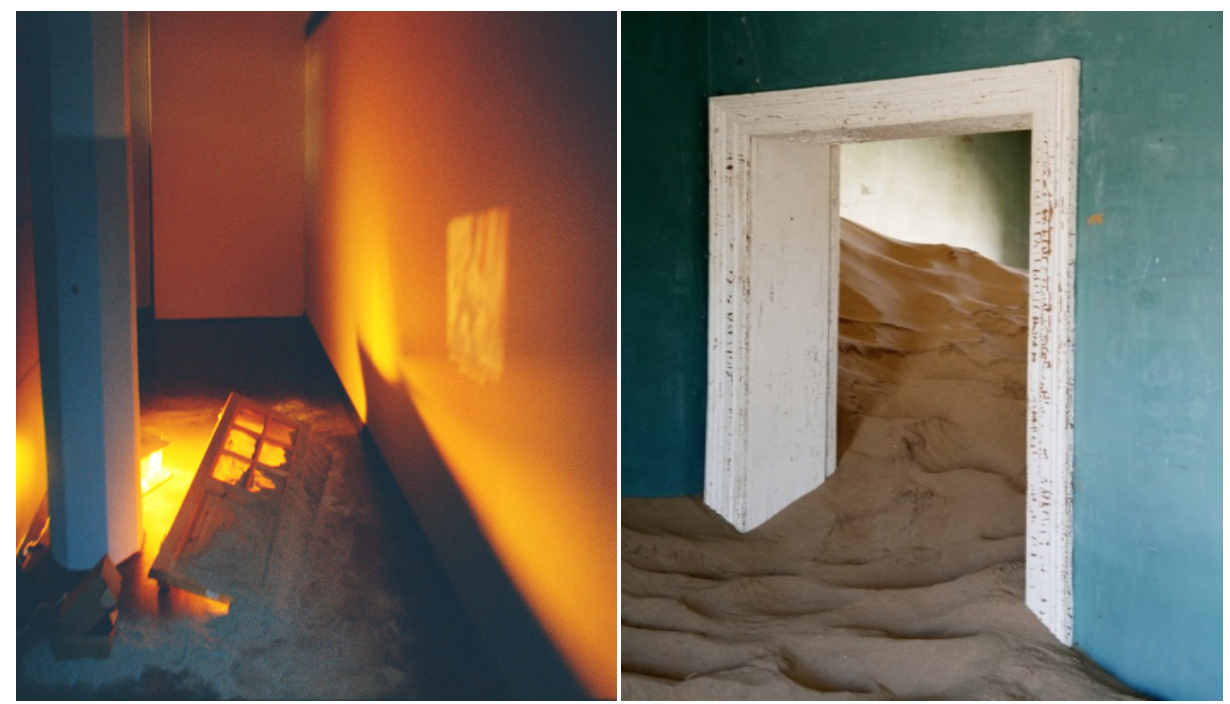

Figure 7. Forgotten spaces through covering with sand: Right: Our installation; left: in Namibia

Source: photocase

\subsubsection{Alternative Photographic Installation}

The second scenographic installation addresses augmented reality. We designed an array of "doors" like before, where the visitors can immerse into the photographs projected, mirrored or shadowed. The digital version goes for stereo images, involving the 3D model and the photograph (Bostenaru, 2012).

The purpose of this installation is an "hommage à Dan Hanganu" and it was proposed for ABC Montreal and is also displayed as proposal on their webpage (http://www.cca.qc.ca/abc_pdfs/134-Bostenaru.pdf-not as publication). Dan Hanganu is a Romanian born Canadian architect (b. 1939, Iaşi). Dan Hanganu is a role model for mobility of architecture. In the author's life way the author there is a search for role models for mobility, being herself mobile between more countries, particularly for role models in architecture, and pathways of bringing European architecture outside Europe, which is currently the topic of a European research network. He is not the first architect entering the pathway from Romania to North America, the CCA also having a rich archive on Rudolph Fränkel, who built in Romania, as a German migrant, and then emigrat over the UK to the US.

The Romanian architect shaped the landscape of Montreal, starting with the search for the routes, at Pointe-à-Callière museum, and became thus equally a representative of his adoptive community. Other representative buildings of Dan Hanganu in Montreal include HEC Montreal, Cirque du Soleil, Nahum Gelber Law Library at McGill, UQAM Design Pavilion (of which we included photos), but also the acclaimed Theatre du Nouveau Monde and the extension of Hotel Godin, and many others. These buildings belong to different decades and exemplify therefore different architecture trends. As such, his buildings belong to contemporary architecture history. We included the McGill Library image into the attachments, although not the best known work, for the diagonal framed window, which may serve as model for prototypes in intervention projects we investigated at other latitudes.

We propose an installation to visualise the relationship of the community with the architecture of Hanganu (Figure 8-9). We will provide an alternative to traditional photo exhibitions, while presenting images. All photographs were taken by the author of the installation in summer 2010 while completing a support grant stay at the CCA, using documentation from newspapers on Dan Hanganu's activity, also from the CCA.

As Dan Hanganu searched for ways of bringing memory to expression, for example at his major work, the Archeology Museum, we try to open three doors to memory: the shadow, the reflection and the projection. The multimedia installation of the doors shall bring all characteristics of the space to which they are doors. It is a 1:1 model allowing involvement of citizens.

An important aspect of conservation is to preserve the memory of the architecture object, which is why we propose an incursion by a multimedia art project, multimedia playing itself a role in conservation interventions for the relationship between old and new. Such a multimedia incursion was done by Hanganu himself in the 
lighting at the Archeology Museum, and in other museums, outside Montreal, and is therefore suitable for the "homage". Although multimedia was brought to architecture already in the interwar time (the Fontana del'Essedra at Mostra d'Oltremare in Naples, Italy), and brought to highest expression to also Romania born Iannis Xenakis, to whom the CCA dedicated an exhibition, we aim to use today's everyday accessible technology to realize the project, and thus integrate with current trends of digital methods in the arts.

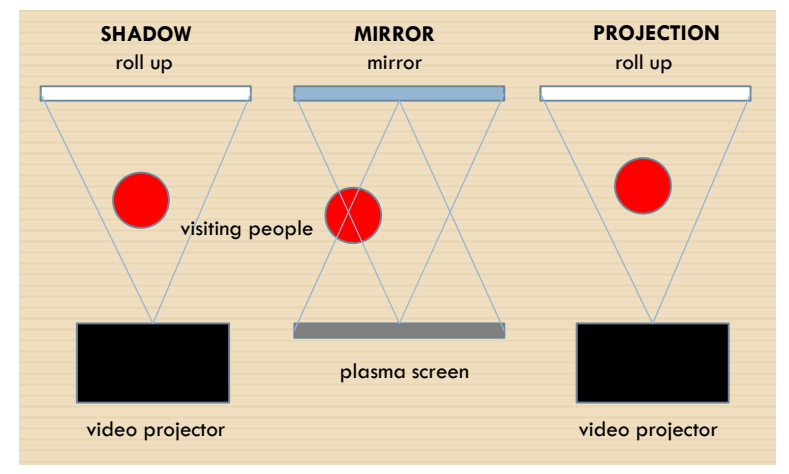

Figure 8. Photographic exhibition layout (CCA proposal)

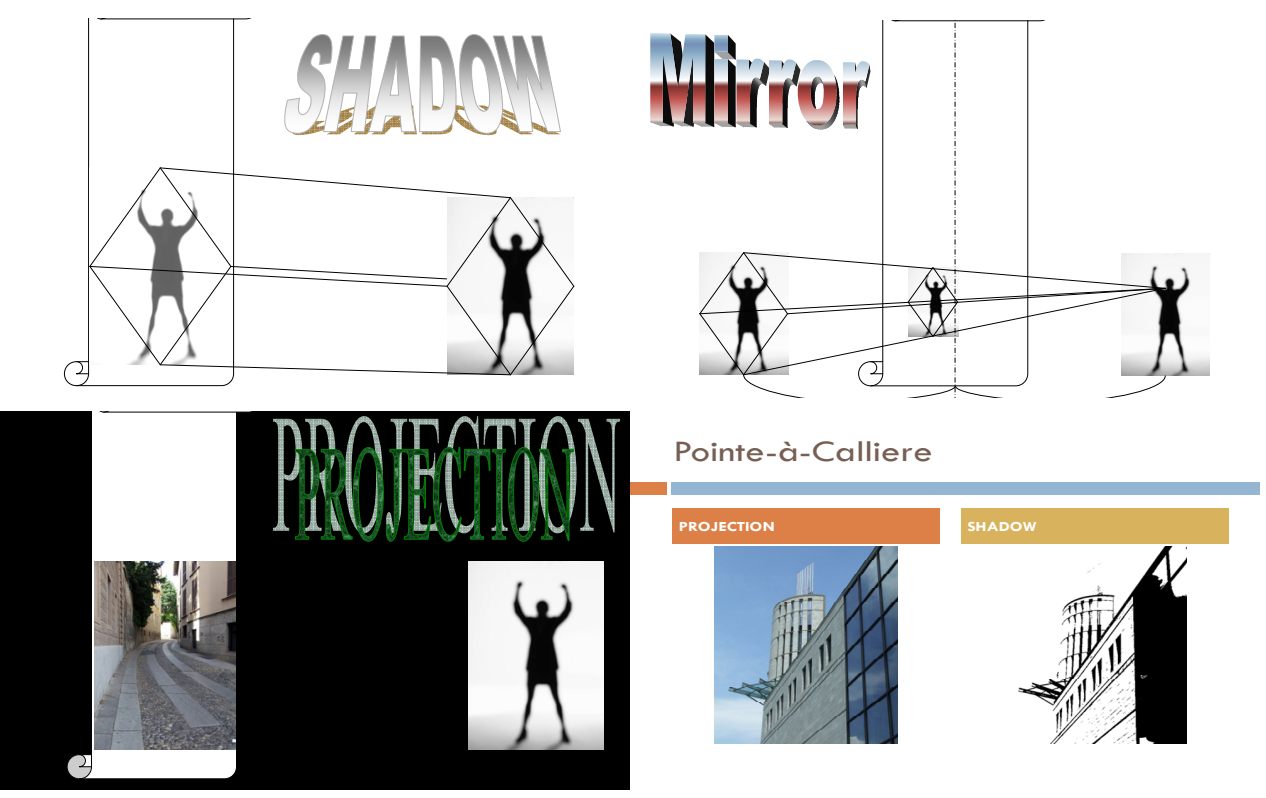

Figure 9. Detailing of the 3D multimedia exhibition

We stress the role of photography. Our support grant at the CCA was on photography, and after all we propose an alternative photo exhibition. Photography has potential for augmented reality in the comparison "then and now". Instead of the classical "then and now" comparison we compare full colour image projection and shadow. And we propose a participative exhibition, where the visitors are projected into the space of the images/shadows - another kind of augmented reality.

The virtual preservation through photography of historic buildings raised the question of keeping the memories of the work. For this reason we undertake a research project, "research by design", on the artistic representation of memory. Initially we conducted research with methods offered by philosophy, phenomenology starting from Heidegger, phenomenology to which we turn and later, when we will involve participatory architecture. We created we defined "the rediscovered space" of buildings by Dan Hanganu. Photography in itself is an access "door" to memory.

We present an installation symbolizing a unique encounter scenography. The doors to the rediscovered space merged a long time ago with the environment. We have a door which belongs to the past, until a space yet known 
was rediscovered, and have a light, the light of today, trying to rediscover, trying to show us a path, or even and what is behind the door, but what we have a glimpse of. When archaeologists are trying to find some signs of a culture that no longer exists, or at least not as it was, they collect some items, and include them in the museum and then say: "You cannot get a sense of culture". The idea that is that very rarely that a museum of cultural attractions really reveals a culture we have built memories of. Therefore we propose this installation inspired by the description in Michael Ende's authored fairy tale of how to enter another world. What we try is exactly make visitors enter the screen, through a 1:1 simulation of virtual reality, not only through glasses as in stereo views.

Such an installation could be also extended to the city, projecting for example on city walls, a new way of painting, having the art of Art Nouveau instead of planted green walls, as we will show in the other, connected proposal, since Dan Hanganu also designed a building with a green wall.

The shadows, the reflection and the projection of photographs of Hanganu architecture in Montreal will be done, while permitting the walk of the public between the two elements of these multimedia doors, and thus the integration of the shadow or the mirroring of the person visiting the installation into the landscape of Hanganu's architecture. Like in Michael Ende's "Neverending story" these doors open from just one side, the one enriched by the multimedia element. From the other side they are opaque. While the roll-ups will be kept vertical, adequate for portrait photography, and rather at the size of a door, the mirror will be horizontal, adequate for landscape orientation photography, proving with this that a door can have any shape. A rather long and shallow space of the CCA, like a corridor, is adequate for this. The shadows will be created through DTP transformation, to create the effect of aluminum foil on traditional slides, to create the effect of projecting a light over a hard copy model. A computer will display on the two screens the shadow and the projection of the same image. All items can be purchased in Canada on the place, and easily installed and des-installed, being possible that the CCA already has some, or, if not, they will be added to the inventory for daily business, as they are adequate for this.

\subsection{Landscape Architecture}

Finally we approached the green wall. While pockets on skeletons to build a green wall can be the boxes of before, for a digital version we can dug among the thorns from Grimm's and Charles Perrault's "sleeping beauty", to find shapes of spaces, like in a Paradise Garden concept, for which we have a model (Figure 11), for example with an image map (Figure 10). Some hints on how fairy tales can be represented in artistic installations have been also given in our paper dealing with the subject of fairy tales Bostenaru and Kauffmann (2013).

"Once upon a time ..." as in the story.

Building gardens is living stories. But once the stories have an end, while gardens are never finished.

The gardens of Paradise was designed in a seminar at the University of Karlsruhe, under the guidance of the late Dieter Kienast landscape architect. Kienast approached this concept in the own work as well (Dean et al., 2004, essay about Paradise by Kienast himself, and related works). The concept is based on the idea of forgetting and rediscovering, garden space retrieval through multiple Paradise "doors" open to the senses. In the garden of Paradise "doors" garden spaces are cut as a network of thorns and then rise once found access, inspired by Grimm's tale "Sleeping Beauty". The interpretation of senses was based on the five elements of Chinese astrology. This concept is not isolated, we applied a research project "spaces of encounter" in particular the "rediscovered space" explained above.

At the beginning of the story the curse is pronounced through which is born a "garden" of rose thorns: "the daughter of the king will stick a fork in the 15th year of life and fall dead." And without speaking a word still the witch turned and left the room. All were terrified, then went before the twelfth, which was still unspoken desire and could not lift the curse, but only sweeten said "there will be death, but a deep sleep for 100 years".

Perhaps Paradise garden is not only missing back asleep but hidden in each of us waiting to be awakened. The expulsion from paradise gardens were an expression of desired images but lost.

A prescribed period of time it remains an inaccessible garden "Around the castle began to grow a bush of thorns, which rises every year, and finally surrounded the whole castle and rose above it, so we do not see anything thereof. [...] But in the country the saga of the lovely Sleeping Beauty has spread, as it was called before the king, so from time to time came the kings be trying to go through the bush to the castle. It was not possible, because spines, as if it was their hands, they hold fast and remains fixed in there youth, could not be released and died a terrible death."

In the Renaissance open grounds were introduced in European gardens. Poliphilo (Colonna, 1499), whose road is planted with forests, caves, ruins, animals in the story, sumptuous palaces, gardens quickly recognize that by 
deciphering strange symbols written on stone for thousands of years can be understood secrets of nature: through knowledge of the physical world can be understood metaphysical world ... the beginning of a dark forest roam Poliphilo dream as for the maze of Ariadne for Theseu.

Garden Maze is our world rich and with networked information. One remains despite his numerous contacts increasingly alone in his inner world, for each individual there is a reality that can not be connected to this network.

And the greatest depths garden is the Paradise. In the Garden of Paradise there are other laws because it is in another world, the inner world of people. No one can be but art can bring to the surface the extent that it comes to knowledge.

But after 100 years the thorns in the garden became roses: “... and came the day when Sleeping Beauty wakes up. When the king's son approached the bush of thorns were only large flowers that are distant from one another by itself and let him pass unharmed and were meeting behind the bush."

Limits mark our world. For Paradise is available but, contrary, endless. Paradise can be reached only disconnecting certain size, and between the time it first.

As eye lace of moment life is in no way shape wear something isolated but toward what is behind life. Life, consisting of independent meshes becomes a series of gates that lead to parallel corridors that lead so the others. Some point becomes for us an unexpected gate that leads to mystical.

Lace life consists of separate plates that disappear the moment the gate to find what shone before behind life. We are heading into what is behind the world without leaving this world.

We walk like a glass smooth, transparent, and below follows us eternal abyss.

Inner world is what lies behind life for us, virtual. It can be accessed only through the senses. They are unexpected doors.

And thus reaches the end of the story, the garden of thorns, like caterpillar into a butterfly, rose garden turned into "And he went on, and everything was so quiet that he could hear his breathing, and finally reached the tower and opened the door to the small room in the Sleeping Beauty slept. There she was lying, and was so beautiful that he could not gaze elsewhere, and leaned over and kissed her. When he touched her with the kiss, Sleeping Beauty opened her eyes, got up, and looked friendly to him.... And then the king celebrated son's wedding with Sleeping Beauty with all pomp, and they lived happy until the end."

In every man there are two polarities, and one of them is the endlessly longing. The other is but worldly life satisfaction. The story ends. Paradise can not live one again because something was enchanted meantime. Paradise itself, the eternal depths, is thus a cycle, which always reach world final arousal feelings and the outer world. Return is as important as the entry, because man can perceive the world lost only by contrast.

In mythology it is described that the "Blue Dragon" lives in a creek in the Far East, where it is morning and where it is found the new beginning of spring. The "White Tiger" live in the west, the mountains, the region of autumnal decay. Morning spring is the symbol of beginning, rising to Yang. Evening and autumn are symbols of the decay, the Yin. Between the "blue dragon" and "white tiger" some have recognized specific intercalation Ying-Yang. The "Black Turtle" lives in the mountains north, being associated midnight and winter. The "Red Bird" lives south, the plains region associated to day and summer. (See also http://de.wikipedia.org/wiki/Chinesische_Astrologie).

In the concept presented was designed garden of Paradise comprised of bush roses are cut different spaces in a labyrinthine sequence, leading to a meditation space. Spaces correspond to the elements, emotions, seasons and times of day as they are expressed in Chinese mythology.

Thus, the center corresponds to the earth, thinking, hot summer, yellow. Around it are arrayed:

- White Tiger: West, Fall, sadness, metal, night;

- Black Turtle: north, winter, fear, water, midnight;

- Blue Dragon: East, Spring, anger, wood, morning;

- Red Bird: southern, summer, joy, fire midday.

Under mythological image of four animals is found correlations Chinese inductive system. Although we recognized intercalation Ying-Yang world is not seen as contradictory pair interdependence, but as evolving phenomenon in five phases. 
In this system into five phases inside and outside, inner and outer world are together, because they are not separate Chinese mythology. There transcendental link between the inner and outer world.

Joy space were chosen elements to express freedom, movement and rhythm, atmosphere, giving the intellect, beautiful music, radiosity, light. It is a game fireworks this space.

For the meditation space was out of scale, we chose isolation, privacy, scattered light, peace, and form without contour. This space is a stone garden, Japanese style.

Sorrow space was chosen simplicity, flowing lines, beautiful light, reflected multiple, white, gray, green and blue, a strong horizontality. This space consists of stepped terraces.

Fear space was chosen a tight space, devoid of landmarks, dark, tense, without stability, noise, lighting vertical surprising appearance. This space is a waterfall that surrounds all rounds.

Space dynamics were chosen slash, hard materials, dignity, strong direction, red, blue and yellow. This space is a lightning-shaped tunnel.

During maze is in the following sequence: sadness (access), fear, dynamic, joy, meditation, after which the cycle repeats. They were ordered according to the cardinal points of mythology.

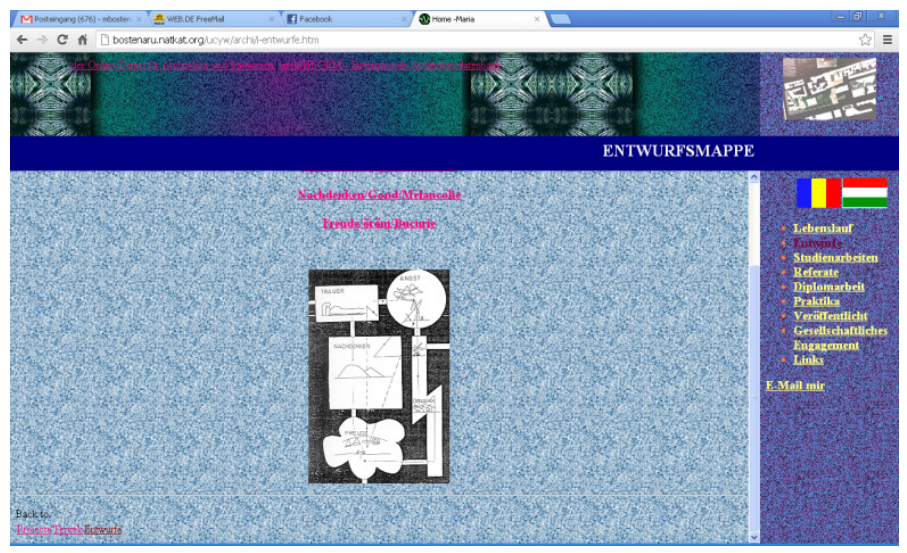

Figure 10. Navigation items through an image map in the webpage of the paradise garden

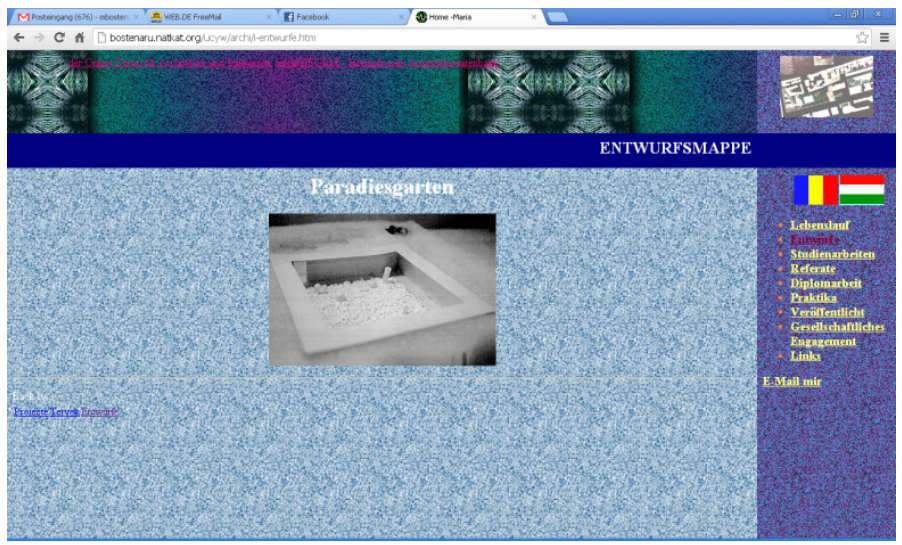

Figure 11. An item (the central garden part) representing a hard copy model to which it can be navigated through the webpage

\section{Discussion and Conclusions}

In this discussion we will focus instead of the representation issues, with the thematic which is represented. Aspects tackled by the research are the digitized concepts themselves. As such, we first deal with the vulnerability of water. A future project we approach is about the dual nature of water, which we experienced interdisciplinarily in a summer school (Bridle et al., 2013). This topic of duality will be the topic of our future 
postdoctoral project as well. Second, we deal with memory. The two concepts can be connected, since the dual nature of water implies water as a hazard, and memory implies also preserving the memory of the heritage habitat from before the catastrophe in the reconstruction afterwards. But the representation of memory is also connected to the following item, the paradise garden, since this is an ancestral memory, a longing for something what we cannot remember from our lives. The scenographic representation of memory is present in the first project of this kind- "rediscovered" means brought back from memory. Also for the second project, instead of Hanganu the "hommage" could be done to Kienast, the adviser of the landscape project, since the landscape architect died, and hommage books are already done (Freytag, 2015). The problematic of memory goes over the limits of this paper, and has been approached in numerous philosophy works, such as Saint Augustine (1987), Nietsche (1873), Heidegger (1927) and goes along with perception and representation of space and time. However, in this paper, like in our project, we tried not only to see digital means as means for representation, but also of analysis. For this reason the relationship with hard copy is important.

The representation of memory is important for learning processes. For example for our current project of exploring the digital representation and analysis of the impact of hazards a mental map of the heritage habitat has to be created, to allow identification of the inhabitants with the reconstruction. Such a mental map, which displays also damages to landmark objects, is at the same time an instrument of "lessons learned". Damage makes us learn on how to reduce vulnerability. As such, the digital simulation, as suggested by Kahn (1966) can lead to learning before the disaster, from the simulated damage. Educational software is nowadays common ground. Education happens assisted by computer. But the works presented here are from pioneering multimedia, and, contemporary to them we would like to refer only one, Brückner (1998). In the field of landscape architecture we approached partially in the first project (urban context, Green Belt) and mainly in the third project, but it could be also approached in the second connected to the third, there are several approaches to teach through media as well. Such one is the one of Nothelfer (2008), or, more recently of Fetzer (http://www.virtuelle-hochschule.de/praxis/erfahrungsberichte/paedagogische-aktionsforschung). They make use of the fact that multimedia can show the rich visual material in plastical/artistic education, and that the item of navigation, imported to the internet, also describes movement in space. Also, the projects presented reflect the learning component in artistic field-from the master. Libeskind, Kramm and Kienast are such masters, practicing architects wo taught students how to make similar projects. Libeskind (2001) shows exactly this connection between theory and practice. And the methodology is also one derived from how plastical language elements can be brought over to school children (Filoteanu \& Marian, 2000), and as such the multimedia applications a good teaching and evaluation material. The third experiment showed the artistic expression of the stereo image. Our work quoted (Bostenaru, 2012) shows the technical background. In the field of this technical background we were teachers ourselves, and this is the field where our works can apply in teaching. Such a work is Bourlotos (2001). Another work at Kramm which we do not present here implies the translation of physical presence knowledge on combination of colours into computer image which we used to create colour perspective in a practica in the Kramm studio. We will work on a paper for the "Education in architecture" Argument session on how to use these multimedia components as computer aided teaching means in artistic education methods as in Filoteanu and Marian (2000). Also, we were active ourselves in a field of teaching how to deal with water, in another form of architecture with water component, the thermal bath. The New York City College of Technology employs a virtual classroom WWW multimedia component in which reviewers from the entire world, such as I, are involved in teaching students there. The student creates an online portofolio such as http://gracydubon.blogspot.ro/2014/05/final-presentation.html to which the reviewer comments on the posted comments. These contents are, however, unlike what we presented in this paper, not converted to the new medium, but photos and screenshots of what is presented in hard copy (drawing, rendering and model), highlighting thus the difference to our WWW portofolio. However, they use free webpage software which does not require HTML programming knowledge. More details can be read in Bouratoglou et al. (2015) and in Dikigoropoulou and Bouratoglou (2014). Also, the teaching relates to learning from masters and transmitting examples of built architecture through direct interaction with such models, in site visits and historical documents consulting. But through the organisation of a progressive portofolio the interaction happens in learning, not in navigation on the screen.

In our current research project we connect investigation on hazards and landscape, the thematic focuses of the artistic projects in this paper. The Magheru boulevard in Bucharest, subject of the research, presents buildings lost in earthquake, and gardens which were lost through urban development. These can be digitally shown in multimedia, or contribute to the shape of the public space through traces and participatory activism, a result of the learning processes. 


\section{Acknowledgments}

Consideration on digital representation of this projects developed previously as results on stays in Germany and Canada, presented in frame of the "Network for Digital Methods in Arts and the Humanities Network" in Hamburg and Bucharest and are part of the postdoctoral grant supported by the strategic grant POSDRU/159/1.5/S/133391, Project "Doctoral and Post-doctoral programs of excellence for highly qualified human resources training for research in the field of Life sciences, Environment and Earth Science" cofinanced by the European Social Found within the Sectorial Operational Program Human Resources Development 2007-2013". The research on water is a pre-research of the Vasile Pârvan fellowship oft he Romanian Education Ministry at the Romanian Academy in Rome.

\section{References}

Szent Ágoston (Hungarian translation Városi István) (1987). Vallomások (Confessiones). Budapest: Gondolat.

Alexander, C., Ishikawa, S., \& Silverstein, M. (1977). A Pattern Language. Towns, Buildings, Construction. New York: Oxford University Press.

Amoroso, N., Hudson-Smith, A., Phillips, M., Speed, C., \& Willis, K. (2013). Patch-Scape; Pads, Pods, Phones and Spatial data. Concept for a workshop at the Digital Landscape Architecture DLA Conference 2013. Retrieved from http://www.kolleg.loel.hs-anhalt.de/landschaftsinformatik/fileadmin/user_upload /_temp_/2013/WorkshopReader/801_PatchScapeFinal_E.pdf

Bostenaru, D. M. (2008). Modern Italian architecture of interwar time-Approaches to the memory of the space. Proceedings of the 16th ICOMOS General Assembly and International Scientific Symposium "Finding the Spirit of the Place". Quebec, Canada. Retrieved from $\mathrm{http}$ ://openarchive.icomos.org/view/creators/Bostenaru_Dan=3AMaria $=3 \mathrm{~A}=3 \mathrm{~A} . \mathrm{html}$

Bostenaru, D. M. (2008). The rediscovered space, a space of encounter. Proceedings of the 16th ICOMOS General Assembly and International Scientific Symposium "Finding the Spirit of the Place", Quebec, Canada. Retrieved from http://openarchive.icomos.org/view/creators/Bostenaru_Dan= 3AMaria $=3 \mathrm{~A}=3 \mathrm{~A} \cdot \mathrm{html}$

Bostenaru, D. M. (2012). Stereo 3D Applications Potential for Heritage Disaster Management. In R. Billen, M. Caglioni, O. Marina, G. Rabino, \& J. R. San (Eds.), 3D Issues in Urban and Environmental Systems. Bologna: Società Editrice Esculapio Srl.

Bostenaru, D. M., \& Kauffmann, M. (2013). Leadership Role Models in Fairy Tales-Using the Example of Folk Art and Fairy Tales, and Novels Especially in Cross-Cultural Comparison: German, Russian and Romanian Fairy Tales, Review of European Studies, 5(3), 40-58.

Bourlotos, G. (2001). Gebäudeaufnahmesystem zur Darstellung der Tragstruktur (Diploma work). University of Karlsruhe.

Bouratoglou, J., Dikigoropoulou, L., Dubon, G., DUBON, B., Dan, M., \& Doczy, P. (2015). Research by design in the architecture of spa-s. Argument. (Section: from the works of students)

Bridle, H., Vrieling, A., Cardillo, M., Araya, Y., \& Hinojosa, L. (2013). Preparing for an interdisciplinary future: A perspective from early-career researchers. Futures, 53, 22-32. http://dx.doi.org/10.1016/j.futures.2013.09.003

Brückner, T. (1998). Ein WWWbasiertes Lernsystem zum Thema Internet (Diploma work). University of Karlsruhe.

Dean, M. R., Weilacher, U., Göbel-Gross, T., Kienast, D., Kienast, E., Ritz, G., \& Rüegg, A. (2004). Dieter Kienast, München: Birkhäuser.

Dikigoropoulou, L., \& Bouratoglou, J. (2014). Global Interaction into the Traditional Design Studios Thru Blogs (pp. 7-10). 4th Annual International Conference on Architecture, Athens, Greece.

Filoteanu, N., \& Marian, D. (2000). Zeichnen und Kunsterziehung. Bucharest: All Educational.

Freytag, A. (2015). Dieter Kienast_Ein Vokabular für die Landschaft (based on PhD thesis at ETHZ 2011). Zurich: GTA.

García, L., \& Montero, V. P. (2010). The Challenges of Digital Art Preservation. E-conservation magazine, 14, 43-53. Retrieved from http://www.e-conservationline.com/content/view/884

Hughes, B. (1999). Dust or Magic, Secrets of Successful Multimedia Design (Reprinted as Creative Work in The 
Digital Age). Harlow: Addison-Wesley.

Kahn, H. (1966). Thinking about the unthinkable. Horizon Press.

Libeskind, D. (2001). The Space of Encounter. New York: Universe.

Nietzsche, F. (2009). On the Use and Abuse of History for Life (Original: Vom Nutzen und Nachteil der Historie fur das Leben, 1873). Retrieved from http://records.viu.ca/ johnstoi/Nietzsche/history.htm

Nothelfer, U. (2008). Landschaftsarchitekturausbildung-zwischen Topos und topologischem Denken: medienpädagogische Grundzüge eines webbasierten Fernstudiums, orientiert an signifikanten Lern- und Lehrerfahrungen in der Landschaftsarchitekturausbildung seit ihren Ursprüngen (After a PhD work at the University of Kaiserslautern). Lübeck: Der Andere Verlag.

Serexhe, B. (Ed.). (2013). Preservation of Digital Art: Theory and Practice. The digital art conservation project. Vienna: Ambra V.

Voigt, A., Aharoni, S., Birken, J., Krell, A., \& Zappe, J. (Eds.). (2010). The Daniel Libeskind Research Studio: Staatliche Hochschule für Gestaltung, 1999-2003. Karlsruhe: Staatliche Hochschule für Gestaltung.

\section{Copyrights}

Copyright for this article is retained by the author(s), with first publication rights granted to the journal.

This is an open-access article distributed under the terms and conditions of the Creative Commons Attribution license (http://creativecommons.org/licenses/by/3.0/). 